J. Winters, W. Dehaen. K. Binnemans, Physical Chemistry Chemical Physics 21, 4053-4062 (2019). DOI: $10.1039 / \mathrm{C} 8 \mathrm{CP} 07041 \mathrm{E}$

\title{
Solvation structure of poly-m-phenyleneisophthalamide (PMIA) in ionic
}

\section{liquids}

\author{
Jonas Winters $^{\dagger}$, Wim Dehaen ${ }^{\dagger}$, Koen Binnemans ${ }^{\dagger *}$
}

${ }^{\dagger}$ KU Leuven, Department of Chemistry, Celestijnenlaan 200F, P.O. box 2404, B-3001

Heverlee, Belgium.

*Corresponding author:

Email: Koen.Binnemans@kuleuven.be

\section{Supporting Information}

Detailed synthetic procedures of ionic liquids, PMIA and aramid compounds, inherent viscosity related equations, as well as the FTIR and ${ }^{13} \mathrm{C}$ NMR spectra used in the spectroscopic analyses are provided in the Electronic Supplementary Information (ESI). 


\begin{abstract}
Polyaramids are a class of high-performance polymers, known for their high mechanical strength and chemical and thermal stability. Their ability to create a network of intermolecular hydrogen bonds causes them to be very poorly soluble in conventional solvents. Hazardous solvents such as N-methylpyrrolidone (NMP) and dimethylacetamide (DMA), in combination with an inorganic salt such as $\mathrm{CaCl}_{2}$, are currently used for the synthesis and processing of polyaramids. Ionic liquids are proposed as suitable greener alternatives. In this work, we studied the solubility and dissolution mechanism of the meta-oriented polyaramid poly-mphenyleneisophthalamide (PMIA) in a wide range of ionic liquids. It was found that, similarly to cellulose, PMIA could be dissolved readily and in large amounts in ionic liquids containing a strongly coordinating anion (such as chloride, acetate and dialkylphosphate) and an imidazolium cation. Hydrogen bonding between the anion and the amide NH of PMIA is the main solvent-solute interaction. An odd-even effect in solubility occurred when altering the length of the side chains on the imidazolium cation. Furthermore, it was found that the presence of hydrogen bond donating $\mathrm{CH}$ moieties on the cation is a necessary condition for dissolution. The exact role of these hydrogen bond donors was investigated by FTIR and ${ }^{13} \mathrm{C}$ NMR spectroscopy. It was found that there is no significant interaction between the hydrogen atoms of the imidazolium ring and the amide carbonyl groups. Rather, the hydrogen bond donors are needed to stabilize the solvation shell around PMIA through alternating cationanion interactions.
\end{abstract}

Keywords: ${ }^{13} \mathrm{C}$ NMR; FTIR; hydrogen bonding; ionic liquids; polymer dissolution; PMIA 


\section{Introduction}

Aramids are a class of polymers that consist of aromatic units connected via amide linkages.

These polymers are considered to be high-performance materials due to their high mechanical strength and temperature resistance. ${ }^{1}$ Well-known commercially available aramids are the allpara oriented poly-p-phenyleneterephthalamide (PPTA) and the all-meta oriented poly- $m$ phenyleneisophthalamide (PMIA). The para-aramid PPTA is a stiff, rigid rod-like polymer that can be processed into highly oriented fibers. ${ }^{2-4}$ The resulting fibers have a very high strength-to-mass ratio, as such they are used for instance as material reinforcement, cutresistant clothing and bulletproof body armor. The more flexible meta-aramid PMIA, on the other hand, trades in some mechanical strength in favor of enhanced processability, and it is used for applications requiring a high thermal resistance such as circuitry insulation and fireprotective clothing. ${ }^{5}$ The superior properties of aramids result from their rigid aromatic backbone, the stability of the amide functionalities and intermolecular hydrogen bonds between these amide functionalities. The NH hydrogen atoms interact with the carbonyl oxygen atoms of nearby polymer chains, creating a vast network of hydrogen bonds. This network, combined with aromatic stacking interactions, results into polymers with a very high degree of crystallinity. ${ }^{6}$ However, the intermolecular hydrogen bonds also cause aramids to be very poorly soluble in conventional organic solvents. This low solubility is a major issue, as aramids can only be synthesized or processed in solution. Their melting point lies above their decomposition temperature, thus precluding processing in the melt. ${ }^{7,8}$

Solvents capable of dissolving aramids have the ability to break up the intermolecular hydrogen bond network. These are polar amide solvents such as hexamethylphosphoramide (HMPA), $N$-methyl-2-pyrrolidone (NMP), $N, N$-dimethyl-acetamide (DMA) or $N, N$ dimethylformamide (DMF), usually in combination with an inorganic salt like $\mathrm{LiCl}$ or $\mathrm{CaCl}_{2}{ }^{9}{ }^{9}{ }^{10}$ The chloride ions in these inorganic salts can interact with the NH hydrogen atoms 
and are capable of interrupting the hydrogen bonds. Although HMPA is the strongest solvent, it is known to be carcinogenic and its use has been discontinued. NMP, DMA and DMF are still being used today but, despite being less dangerous than HMPA, these solvents are suspected to be reproductive toxins. As a result, they have been placed on a 'Substance of Very High Concern' (SVHC) list by the European Commission. ${ }^{11}$ This means that these solvents will be subject to REACH regulation, and their use will likely be restricted in the future.

The use of amide solvents in the aramid industry could potentially be avoided by using ionic liquids as greener alternatives. Ionic liquids are solvents composed entirely of ions. ${ }^{12,13}$ Due to their negligible vapor pressure, low flammability, and high recyclability, they are considered to be desirable replacements for volatile organic compounds (VOC's). ${ }^{14,15}$ Known to be designer solvents, their physical and chemical properties can be tuned through functionalization and selection of the cation and anion. Ionic liquids are already well known suitable replacements for hazardous solvents regarding the dissolution of cellulose. ${ }^{16,17}$ Similarly to aramids, cellulose can form a vast network of hydrogen bonds between its many hydroxyl groups. ${ }^{18}$ Researchers have used the designer aspect of ionic liquids to find solvents with good solubility, and other desirable properties, that can serve for the derivatizing, valorizing and processing of cellulose. ${ }^{19-23}$ Furthermore, it has been shown that mixing ionic liquids with suitable co-solvents can facilitate the dissolution process while still retaining high solubilities. ${ }^{24-26}$

The solubility of cellulose is mainly determined by the properties of the cations and anions. A strongly coordinating anion, such as chloride, acetate and dialkylphosphate, is required to have a sufficiently strong interaction with the hydroxyl groups in order to break up the hydrogen bonds. ${ }^{16,27}$ The interaction between the anion and the cellulose chain is generally considered to be the most important factor in the dissolution process, but the influence of the 
cation should certainly not be underestimated. For instance, ionic liquids with pyridinium or imidazolium cations are usually much stronger solvents for cellulose than those containing quaternary phosphonium or ammonium cations. ${ }^{28,29}$ The exact role of the cation in the dissolution process, however, is still fairly ambiguous. The cations have two possible ways of interacting with the cellulose chains: (1) through the formation of weak hydrogen bonds between acidic hydrogen atoms of the cation and the hydroxyl oxygen atoms ${ }^{30-34} ;(2)$ through dispersion interactions between the aromatic cation and the nonpolar domains of the cellulose chains. ${ }^{29,30,35-37}$ The relative significance of these two types of interaction remains a topic of debate. However, it is commonly accepted that the cations that make up strong solvents generally contain a heterocyclic aromatic ring with acidic hydrogen atoms capable of hydrogen bonding.

Ionic liquids are also capable of breaking up the hydrogen bond network of amide-containing polymers such as proteins, ${ }^{38-42}$ aliphatic polyamides ${ }^{43,44}$ and functionalized aramids. ${ }^{45-47}$ Vygodski et al. were able to synthesize low molar mass PPTA using 1,3-dibutylimidazolium bromide and tetrafluoroborate as solvents ${ }^{45}$, whereas Zhao et al. managed to spin PMIA fibers out of a solution of PMIA in 1-butyl-3-methylimidazolium chloride. ${ }^{48}$ Our research group has previously reported on the dissolution mechanism of PPTA oligomers in ionic liquids ${ }^{49}$ and on the synthesis of high molar mass PPTA in ionic liquids ${ }^{50}$ and ionic liquid/co-solvent mixtures. ${ }^{51}$ Unexpectedly, it was found that ionic liquids containing a quaternary phosphonium cation were better solvents for low molar mass PPTA oligomers than their imidazolium counterparts, while the opposite was true for the synthesis of high molar mass PPTA. This discrepancy could not be explained at that time.

In this paper, the dissolution of PMIA in ionic liquids is investigated in more detail, to get a better understanding of the dissolution behavior of aramids and find potential replacements for amide solvents. This meta-aramid was used because, in contrast to high molar mass PPTA, 
it is actually possible to dissolve high molar mass PMIA in certain ionic liquids. This gave the advantage that in this work, we could directly study the dissolution mechanism of high molar mass polymers, rather than having to rely solely on oligomer model compounds. Several ionic liquids were screened for their ability to dissolve PMIA, and in-depth dissolution tests were performed to study the influence of the cation and the anion on the solubility. FTIR and ${ }^{13} \mathrm{C}$ NMR spectroscopy were employed to determine the specific sites of interaction on the ionic liquids as well as the aramids. High molar mass PMIA and aramid model compounds were used in tandem to get a more in-depth perspective. This finally enabled us to propose a potential solvation structure for aramids in ionic liquids.

\section{Experimental}

\section{Products}

All the commercially available ionic liquids were purchased from IoLiTec (Heilbronn, Germany), Cytec (New Jersey, USA), or Sigma-Aldrich (Diegem, Belgium). Isophthaloyl chloride ( $\geq 99 \%$ ), acetaldehyde (99\%), toluenesulfonylmethyl isocyanide (98\%), methylamine 2.0 M solution in methanol, 1-butylimidazole (99\%), 1-octylimidazole ( $\geq 98 \%), 1$ chloropentane (99\%), 1-chloroheptane (99\%), 1-chlorononane (98\%), potassium tert-butoxide (99\%), lithium bis(trifluoromethanesulfonyl)imide (>98\%), deuterium oxide (99.9 atom\% D), $\alpha$-picoline lonza quality ( $\geq 99 \%), \mathrm{Pd} / \mathrm{C} 5 \%$ loading, $N$-methylpyrrolidone extra dry $(99.5 \%)$, diethyl ether $(\geq 99 \%)$ and anhydrous dichloromethane (>99.8\%) were purchased from Sigma-Aldrich (Diegem, Belgium). 3-Nitroaniline (98\%), aniline (99.8\%), pphenylenediamine (>99\%), benzoyl chloride (99\%), trimethylamine (99\%), 1methylimidazole (99\%), 1-chloropropane (99\%), stabilized methyl iodide (99\%), sulfuric acid (96\%), extra dry acetonitrile (99.9\%), ethyl acetate (99.5\%), methanol (99\%) and extra dry $N, N$-dimethylformamide (99\%) were purchased from Acros Organic (Geel, Belgium). Anhydrous potassium carbonate (99\%), m-phenylenediamine (99\%) and 1-chlorooctane 
(99\%) were purchased from Chem-Lab (Zedelgem, Belgium). 1-Ethylimidazole (>98\%) and 1-propylimidazole (>98\%) were purchased from IoLiTec (Heilbronn, Germany). $p$ Phenylenediamine (99+\%) and $m$-phenylenediamine (99\%) were purified by sublimation at reduced pressure on a Schlenk line at $90{ }^{\circ} \mathrm{C}$ and $50{ }^{\circ} \mathrm{C}$, respectively. $\alpha$-Picoline was dried using molecular sieves ( $4 \AA$ ) until the water content was below 50 ppm. All other compounds were used as received, without any further purification. The synthesis and characterization of polyaramid model compounds and PMIA are described in the Electronic Supplementary Information (ESI).

\section{Instrumentation}

The ${ }^{13} \mathrm{C}$ NMR spectra (100 MHz and $150 \mathrm{MHz}$ ) were measured on a Bruker Avance 400 $\mathrm{MHz}$ and $600 \mathrm{MHz}$ NMR spectrometer, respectively. A capillary filled with $\mathrm{D}_{2} \mathrm{O}$ was used as external lock reference and all measurements were performed at $90{ }^{\circ} \mathrm{C}$. The NMR spectra were analysed using TopSpin 4.0.2 software. Fourier transform infrared spectroscopy (FTIR) measurements were performed on a Bruker Vertex 70 spectrometer with the attenuated total reflectance module (Platinum ATR) equipped with diamond crystal. The FTIR data were processed using OPUS 7.5 software. Water content was measured on a Karl Fischer DL39 coulometer from Mettler-Toledo. The inherent viscosity of the PMIA sample was determined using a certified calibrated Ubbelohde $10-100 \mathrm{~mm}^{2} / \mathrm{s}(0.1 \mathrm{~K})$ capillary viscometer from SI analytics in a Lauda thermostated water bath.

\section{Determination of inherent viscosity}

Dried PMIA (0.1 g) was dissolved in $20 \mathrm{~mL}$ of concentrated sulfuric acid (96\%), in order to obtain a PMIA/sulfuric acid solution with a concentration (c) of $0.5 \mathrm{~g} \mathrm{dL}^{-1}$. An Ubbelohde capillary viscometer, placed in a water bath at $25^{\circ} \mathrm{C}$, was used to measure the flow times of pure sulfuric acid ( $\left.\mathrm{t}_{\text {solvent }}\right)$ and of the PMIA/sulfuric acid solution ( $\left.\mathrm{t}_{\text {solution }}\right)$. From these flow times, the relative viscosity of the solution $\left(\eta_{\text {rel }}\right)$, and subsequently the inherent viscosity $\left(\eta_{\text {inh }}\right)$ 
were calculated as a measure for the molecular weight of the polymer. Detailed calculations are provided in the ESI.

\section{Dissolution of PMIA in ionic liquids}

Prior to the dissolution experiments, all compounds were thoroughly dried. PMIA and the aramid model compounds were dried overnight in a vacuum oven at $50{ }^{\circ} \mathrm{C}$. The ionic liquids were dried on a Schlenk line at $70{ }^{\circ} \mathrm{C}$, or higher if the melting point of the ionic liquid was higher. The ionic liquids were considered dry if their water content was below 200 ppm, measured via Karl Fischer titration. Approximately $2 \mathrm{~g}$ of ionic liquid was then transferred to a $25 \mathrm{~mL}$ flask equipped with a stirring bar and a valve. PMIA was then added in fractions of 1 wt $\%$. After each addition, the flask was reattached to the Schlenk line at $90{ }^{\circ} \mathrm{C}$ and left to stir. The solubility was then determined by continually adding fractions of $1 \mathrm{wt} \%$, up until the concentration at which the solution looked turbid rather than transparent. The solubility was then also calculated in terms of mol\%, as the large variance in the molar mass of ionic liquids might skew the trends. For these calculations we used the molar mass of the repeating unit of PMIA, being $238 \mathrm{~g} \mathrm{~mol}^{-1}$.

\section{Results and discussion}

\section{Dissolution experiments of PMIA}

The solubility of PMIA $\left(\eta_{\text {inh }}=2.11 \mathrm{dL} \mathrm{g}^{-1}\right)$ was determined in a wide range of commercially available and synthesized ionic liquids. The ionic liquids consisted of different combinations of cations and anions, which are depicted in Figure 1. The results of the dissolution experiments, reported both in terms of $\mathrm{wt} \%$ and $\mathrm{mol} \%$, due to the large variance of molar mass for the different ionic liquids, are shown in Table 1. Some ionic liquids were able to dissolve large amounts of PMIA, reaching as much as 24 mol\% for 1-methyl-3octylimidazolium chloride $\left(\left[\mathrm{C}_{8} \mathrm{MIm}\right][\mathrm{Cl}]\right)$. This in contrast to PPTA, which is generally much less soluble. The meta-orientation of PMIA causes the polymer to be less crystalline than its 
para counterpart PPTA, making it much more soluble. These solubilities are more

comparable to those for cellulose, and are sufficient for synthesis and processing purposes.

The type of cations and anions that comprised the ionic liquids greatly influenced the

solubility of PMIA. This influence of the anion and the cation will be discussed separately

throughout this paper.

\section{Cations}

\section{Anions}<smiles>[R]N1[C+]N([R])[N+]([R])=C1</smiles>

$$
\mathrm{R}^{1} \mathrm{R}^{3} \mathrm{Im}^{+}
$$<smiles>[R]OP(=O)([O-])[O-]</smiles><smiles>[R]O[Na]</smiles><smiles>N#C[SeH-]</smiles>

$\mathrm{SCN}^{-}$<smiles>[R][PH]([R])([R])C</smiles>

$\mathrm{P}_{\mathrm{R}^{\prime} \mathrm{RRR}}^{+}$<smiles>CC(=O)[O-]</smiles>

$\mathrm{OAc}^{-}$<smiles>N#C[N-]C=N</smiles>

$\mathrm{DCA}^{-}$<smiles>[R]N([R])[R]</smiles>

$\mathrm{N}_{\mathrm{R}^{\prime} \mathrm{RRR}}^{+}$<smiles>[O-][BiH3-]</smiles><smiles>[O]N(S(=O)(=O)C(F)(F)F)S(=O)(=O)C(F)(F)F</smiles>

Figure 1: Different cations and anions of the ionic liquids used in this work, along with their abbreviations.

Table 1: Solubility of PMIA in several ionic liquids. Solubilities were determined at $90{ }^{\circ} \mathrm{C}$

\begin{tabular}{lcc}
\hline \multicolumn{1}{c}{ Solvent } & Solubility $(\mathbf{w t} \%)^{\text {a }}$ & Solubility $(\mathbf{m}$ \\
\hline$\left[\mathrm{C}_{8} \mathrm{MIm}\right][\mathrm{Cl}]$ & 25 & 24 \\
{$\left[\mathrm{C}_{2} \mathrm{MIm}\right]\left[\mathrm{Et}_{2} \mathrm{PO}_{4}\right]$} & 17 & 19 \\
{$\left[\mathrm{C}_{6} \mathrm{MIm}\right][\mathrm{Cl}]$} & 20 & 17 \\
{$\left[\mathrm{C}_{4} \mathrm{MIm}\right][\mathrm{Cl}]$} & 23 & 17 \\
{$\left[\mathrm{C}_{4} \mathrm{MIm}\right][\mathrm{OAc}]$} & $15^{\mathrm{b}}$ & $13^{\mathrm{b}}$ \\
{$\left[\mathrm{C}_{1} \mathrm{MIm}\right]\left[\mathrm{Me}_{2} \mathrm{PO}_{4}\right]$} & 10 & 9.3 \\
{$\left[\mathrm{C}_{2} \mathrm{MIm}\right][\mathrm{OAc}]$} & $12^{\mathrm{b}}$ & $8.6^{\mathrm{b}}$ \\
{$\left[\mathrm{C}_{2} \mathrm{MIm}\right][\mathrm{Cl}]$} & 11 & 6.8 \\
{$\left[\mathrm{C}_{4} \mathrm{MIm}\right][\mathrm{Br}]$} & 7.0 & 6.4 \\
{$\left[4-\mathrm{Me}-\mathrm{C}_{4} \mathrm{MIm}\right][\mathrm{Cl}]$} & 5.0 & 4.0 \\
{$\left[2-\mathrm{Me}-\mathrm{C}_{4} \mathrm{MIm}\right][\mathrm{Cl}]$} & 2.0 & 1.6 \\
{$\left[\mathrm{C}_{2} \mathrm{MIm}\right][\mathrm{Br}]$} & 1.0 & 0.8 \\
{$\left[\mathrm{P}_{2444}\right]\left[\mathrm{Et}_{2} \mathrm{PO}{ }_{4}\right]$} & 0.0 & 0.0 \\
{$\left[\mathrm{P}_{14666}\right][\mathrm{Cl}]$} & 0.0 & 0.0 \\
{$\left[\mathrm{P}_{14666}\right][\mathrm{NTf}$} & 0.0 & 0.0
\end{tabular}




\begin{tabular}{|c|c|c|}
\hline$\left[\mathrm{P}_{4444}\right][\mathrm{Cl}]$ & 0.0 & 0.0 \\
\hline$\left[\mathrm{P}_{4444}\right][\mathrm{Br}]$ & 0.0 & 0.0 \\
\hline$\left[\mathrm{C}_{4} \mathrm{MIm}\right]\left[\mathrm{NTf}_{2}\right]$ & 0.0 & 0.0 \\
\hline$\left[\mathrm{C}_{4} \mathrm{MIm}\right][\mathrm{DCA}]$ & 0.0 & 0.0 \\
\hline$\left[\mathrm{C}_{4} \mathrm{MIm}\right][\mathrm{SCN}]$ & 0.0 & 0.0 \\
\hline$\left[\mathrm{C}_{2} \mathrm{MIm}\right][\mathrm{DCA}]$ & 0.0 & 0.0 \\
\hline$\left[\mathrm{N}_{1888}\right][\mathrm{Cl}]$ & 0.0 & 0.0 \\
\hline$\left[\mathrm{N}_{2222}\right][\mathrm{Cl}]$ & 0.0 & 0.0 \\
\hline$\left[\mathrm{N}_{4444}\right][\mathrm{OAc}]$ & 0.0 & 0.0 \\
\hline
\end{tabular}

\section{Role of the anion}

The solubility of PMIA in ionic liquids greatly depends on the type of anion used. ILs with weakly coordinating anions, such as $\mathrm{NTf}_{2}^{-}, \mathrm{DCA}^{-}$and $\mathrm{SCN}^{-}$, were all unable to dissolve PMIA, regardless of their counter-cation. On the other hand, some ionic liquids containing strongly coordinating anions, such as $\mathrm{Cl}^{-}, \mathrm{AcO}^{-}$and $\mathrm{R}_{2} \mathrm{PO}_{4}^{-}$, were good solvents. Anions with a high hydrogen bond basicity are required in order to break up this intermolecular hydrogen bond network, by interacting with the amide $\mathrm{NH}$ hydrogen atom.

Evidence for interactions between the amide $\mathrm{NH}$ hydrogen atoms and the IL anions can be found by looking at the amide II band in the FTIR spectrum of PMIA. The amide II band is largely caused by N-H in-plane bending, and is thus sensitive to changes in hydrogen bond strength. The stronger the hydrogen bonds on the amide $\mathrm{NH}$, the higher the wavenumber of the band. ${ }^{52}$ For neat PMIA this band absorbs at $1532 \mathrm{~cm}^{-1}$, but when dissolved in an ionic liquid, the band shifts to higher wavenumbers (Figure 2). This indicates that the aramid experiences stronger hydrogen bonding in solution. $\mathrm{NH}$-anion coordination is preferred over $\mathrm{NH}-\mathrm{OC}$ coordination, and thus the intermolecular hydrogen bond network is interrupted.

Another important observation is that the magnitude of the shift, and thus the strength of the $\mathrm{NH}$-anion coordination, differs for each ionic liquid. The dialkylphosphate ionic liquid (green 
curve) displays the highest shift, followed by the chlorides (red and magenta) and finally the bromide (blue). This is in agreement with the trend in hydrogen bond basicity of these ionic liquids, which is entirely determined by the type of anion if the counter anions are similar in structure. ${ }^{53}$ When looking at table 1 , it is clear that anions with higher hydrogen bond basicities result in higher solubilities. This implies that an ionic liquid, consisting of a 1methyl-3-octylimidazolium cation, and a dialkylphosphate anion, could potentially yield an even higher solubility than any of the ionic liquids reported here.

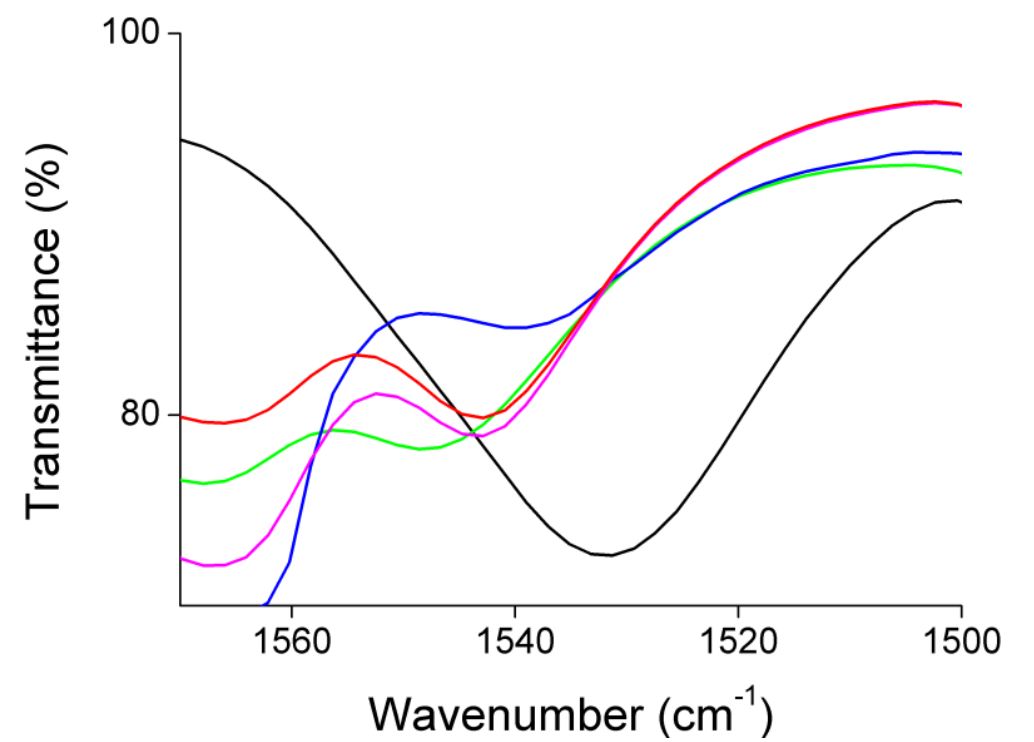

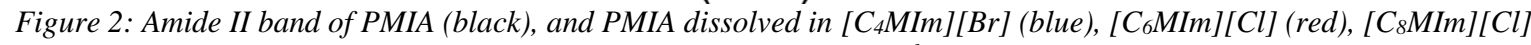
(magenta) and $\left[\mathrm{C}_{2} \mathrm{MIm}\right]\left[\mathrm{Et}_{2} \mathrm{PO}_{4}\right]$ (green). The extra band at $\sim 1565 \mathrm{~cm}^{-1}$ is an ionic liquid vibrational mode.

The role of the anion in the dissolution process of PMIA is clearly to break up the intermolecular hydrogen bonds. To determine the influence of the anion if there were none of these intermolecular hydrogen bonds, the PMIA sample was modified by replacing the hydrogen bond donating $\mathrm{NH}$ hydrogen atoms with methyl groups, thereby removing its ability to form a hydrogen bond network. Unexpectedly, it was found that none of the ionic liquids in Table 1 were able to dissolve the methylated PMIA. It seems, paradoxically enough, that the ability of aramids to form a hydrogen bond network is actually required to make them soluble in ionic liquids. The interaction between anion and amide $\mathrm{NH}$ is the main solvent-solute interaction. Any potential interactions between the cation and the aramid, be it through 
dispersion forces or hydrogen bonding, are too weak to effectively dissolve the aramid on their own. The cations are probably only able to form a solvation shell around the polymer if they are attracted by the anions that are interacting with the polymer. The role of the anion is therefore not just to break up the intermolecular hydrogen bonds, but it also provides the necessary attraction between the ionic liquid and the aramid required to bring the aramid into solution. This is illustrated in Figure 3.
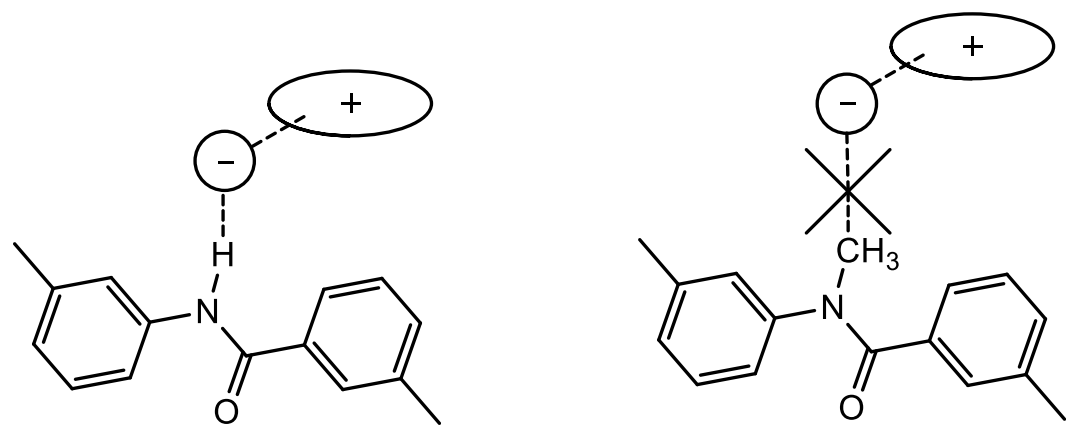

Figure 3. Schematic representation of the attraction of the ionic liquid towards the polymer trough hydrogen bonding. The methylated PMIA can no longer form hydrogen bonds with the ionic liquid and cannot be dissolved.

\section{Influence of the cation}

The solubility of PMIA in ionic liquids is also determined by the type of cation. It was found that PMIA readily dissolves in ionic liquids that contain an imidazolium cation, whereas this polymer is insoluble in those containing quaternary phosphonium and ammonium cations.

(These findings are in conflict with our earlier observations made for PPTA. ${ }^{49}$ An explanation for this is provided in the ESI.) Furthermore, subtle structural differences between imidazolium ionic liquids with the same anion have a significant impact on the solubility. For instance, replacing the aromatic hydrogen atoms on the 2 and 4 positions with methyl groups (1-butyl-2,3-dimethylimidazolium chloride [2-Me-C$\left.{ }_{4} \mathrm{MIm}\right][\mathrm{Cl}]$ and 1-butyl-2,4dimethylimidazolium chloride [4-Me- $\left.\left.\mathrm{C}_{4} \mathrm{MIm}\right][\mathrm{Cl}]\right)$ drastically lowers the ionic liquid's ability to dissolve PMIA. These hydrogen atoms are strong hydrogen bond donors, due to them being placed on a positively charged aromatic ring. ${ }^{54}$ The presence of these acidic aromatic 
hydrogen atoms is an important requisite for cellulose dissolution as well. Their ability to form hydrogen bonds with the hydroxyl oxygen atoms is often used as an explanation. In the case of aramids, they could potentially interact with the amide carbonyl oxygen atoms.

Another structural factor that can influence the solubility of PMIA is the length of the alkyl chain on the 1 or 3 positions of the imidazolium center. Figure 4 shows the solubility of PMIA in $\left[\mathrm{C}_{\mathrm{n}} \mathrm{MIm}\right][\mathrm{Cl}]$ ionic liquids, with the length of the alkyl chain on the 1 position ranging from $\mathrm{n}=2$ to 10 carbon atoms. The solubility of PMIA in imidazolium chlorides displays an odd-even effect, similar to that of cellulose. ${ }^{19,55}$ Ionic liquids with an even number of carbon atom in the alkyl chain are generally the better solvents. No explanation for the occurrence of this odd-even effect has been found so far, but it is likely related to the packing efficiency in the solvation shell around the polymer. Another observation is that the solubility increases with increasing chain length, until reaching a maximum in $\left[\mathrm{C}_{8} \mathrm{MIm}\right][\mathrm{Cl}]$ for the even numbered chains, and $\left[\mathrm{C}_{7} \mathrm{MIm}\right][\mathrm{Cl}]$ for alkyl chain with an odd number of carbon atoms. This behavior is similar to that of PPTA. ${ }^{51}$ The longer alkyl chains result in a bulkier solvation shell around PMIA, which can separate the polymer chains more effectively. However, the longer alkyl chains shield the acidic, hydrogen atoms by steric hindrance, and reduces their hydrogen bond acidity due to inductive effects. ${ }^{56}$

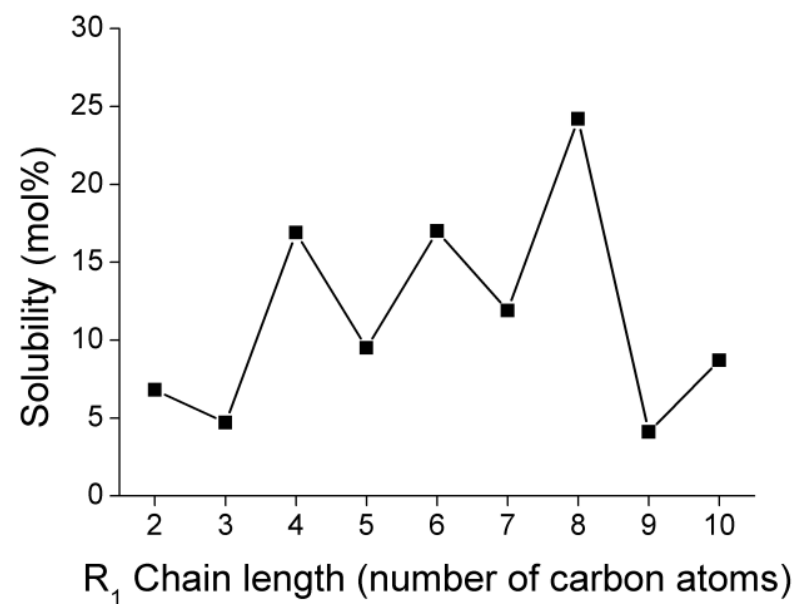

Figure 4: Effect of the $R^{l}$ chain length on the solubility of PMIA in [C $\left.{ }_{n} \mathrm{MIm}\right][\mathrm{Cl}]$ ionic liquids, with $n=2$ to 10 carbon atoms. 
Altering the length of the alkyl chain on the 3-position of imidazolium chlorides has a significant negative impact on the solubility of PMIA. This can be clearly seen in Figure 5. Replacing the 3-methyl group of $\left[\mathrm{C}_{8} \mathrm{MIm}\right][\mathrm{Cl}]$ with an ethyl group already drastically reduces the solubility. The extra steric hindrance provided by another long alkyl group limits access to the acidic hydrogen atoms, and likely hinders the formation of a stable solvation shell. Further increasing the chain length of $\left[\mathrm{C}_{8} \mathrm{C}_{\mathrm{n}} \operatorname{Im}\right][\mathrm{Cl}]$ up to $\mathrm{n}=5$ again causes an odd-even effect. However, this time it is the alkyl chains with an odd number of carbon atoms that result in higher solubilities.

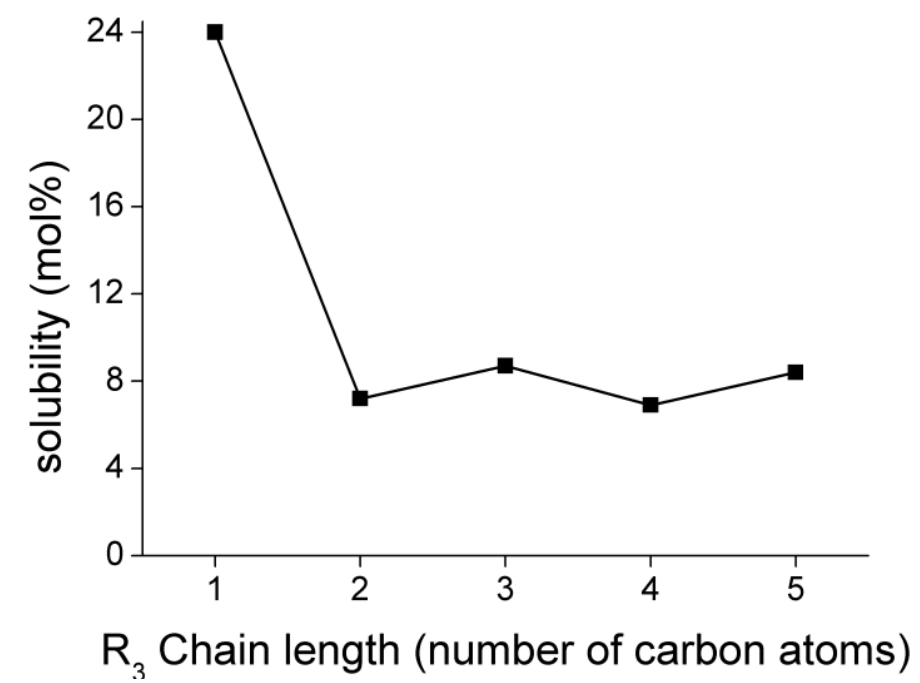

Figure 5: Effect of the $R^{3}$ chain length on the solubility of PMIA in $\left[C_{8} C_{n} I m\right][C l]$ ionic liquids, with $n=1$ to 5 carbon atoms.

\section{Spectroscopic analysis of cation hydrogen bond donating sites}

The importance of the presence of hydrogen bond donors on the imidazolium cation prompted further investigation. ${ }^{13} \mathrm{C}$ NMR spectroscopy is a useful method to study hydrogen bonding in ionic liquids. ${ }^{54}$ Spectra were measured for both neat $\left[\mathrm{C}_{8} \mathrm{MIm}\right][\mathrm{Cl}]$ and for $\left[\mathrm{C}_{8} \mathrm{MIm}\right][\mathrm{Cl}]$ containing $20 \mathrm{wt} \%$ PMIA. No peaks for PMIA could be distinguished, due to its low concentration and the high viscosity of the samples. The ionic liquid, however, yielded clear 
and sharp peaks. The results are summarized in Table 2 . The aromatic ${ }^{13} \mathrm{C}$ nuclei show a shift upfield upon dissolution of the polymer. This upfield shift is an indication that the hydrogen bonds on the aromatic CHs are weakened. This can be explained by the fact that the chloride counter anions, which would normally coordinate strongly with the cation, are now being shared with the polymer, through coordination with the amide NHs. The shift of $\mathrm{C}_{2}$ is much larger than the shift for $\mathrm{C}_{4}$ and $\mathrm{C}_{5}$, probably due to the higher acidity of the $\mathrm{C}_{2} \mathrm{H}$ hydrogen atom. $\mathrm{C}_{4}$ has the lowest shift of the 3 aromatic carbons, indicating that the $\mathrm{C}_{4} \mathrm{H}$ hydrogen atom experiences a rather minor change in hydrogen bond strength upon dissolution of PMIA, compared to the other aromatic hydrogens.

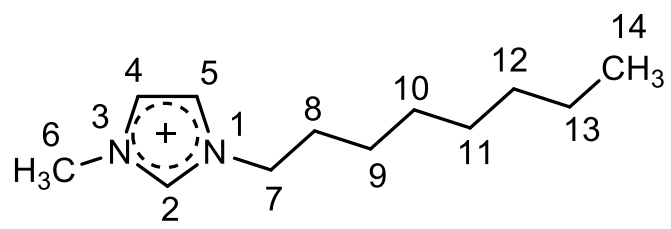

Figure 4: Schematic representation of [C $8 \mathrm{MIm}][\mathrm{Cl}]$ with skeletal numbering

Table 2: Absolute NMR shifts (ppm) of the ${ }^{13} \mathrm{C}$ nuclei of neat [C8MIm][Cl] and [C8MIm][Cl] containing 20 wt\% PMIA.

\begin{tabular}{ccccccccccccc}
\hline $\mathrm{wt}_{\%}$ & $\mathrm{C}_{2}$ & $\mathrm{C}_{4}$ & $\mathrm{C}_{5}$ & $\mathrm{C}_{6}$ & $\mathrm{C}_{7}$ & $\mathrm{C}_{8}$ & $\mathrm{C}_{9}$ & $\mathrm{C}_{10}$ & $\mathrm{C}_{11}$ & $\mathrm{C}_{12}$ & $\mathrm{C}_{13}$ & $\mathrm{C}_{14}$ \\
\hline 0 & 140.41 & 126.47 & 125.42 & 38.84 & 51.72 & 32.58 & 28.54 & 31.30 & 31.25 & 33.97 & 24.73 & 16.16 \\
20 & 140.09 & 126.28 & 125.18 & 38.68 & 51.72 & 32.44 & 28.45 & 31.21 & 31.14 & 33.87 & 24.65 & 16.10 \\
\hline$\Delta \delta$ & $\mathbf{0 . 3 2}$ & $\mathbf{0 . 1 9}$ & $\mathbf{0 . 2 4}$ & 0.16 & 0 & 0.14 & 0.09 & 0.09 & 0.11 & 0.10 & 0.08 & 0.06 \\
\hline
\end{tabular}

To get a more detailed perspective on the effect of PMIA dissolution on the hydrogen bond donating sites, more ${ }^{13} \mathrm{C}$ NMR spectra were measured at varying concentrations. Figure 5 shows the aromatic region of spectra from solutions of PMIA in $\left[\mathrm{C}_{8} \mathrm{MIm}\right][\mathrm{Cl}]$ with concentrations ranging from $0 \mathrm{wt} \%$ to $20 \mathrm{wt} \%$. The influence of the increasing polymer concentration on the aromatic ${ }^{13} \mathrm{C}$ peaks is quite substantial. At a PMIA concentration of $5 \mathrm{wt} \%$, the $\mathrm{C}_{2}$ and $\mathrm{C}_{5}$ peaks start to split up into two separate peaks. The splitting of peaks implies that at these concentrations, $\left[\mathrm{C}_{8} \mathrm{MIm}\right][\mathrm{Cl}]$ is present in two different chemical environments, and that the transition between those environments is slower than the NMR 
timescale. The upfield peak indicates a chemical environment in which the aromatic $\mathrm{CHs}$ experience weakened hydrogen bonding. Therefore, the upfield peak represents $\left[\mathrm{C}_{8} \mathrm{MIm}\right][\mathrm{Cl}]$ in close proximity to PMIA, whereas the downfield peak represents $\left[\mathrm{C}_{8} \mathrm{MIm}\right][\mathrm{Cl}]$ in the bulk. The largest splitting is observed for $\mathrm{C}_{2}$, for reasons explained above. On the other hand, $\mathrm{C}_{4}$ shows no signs of peak splitting, which means that the chemical environment of $\mathrm{C}_{4}$ in solution does not differ much from the chemical environment in the bulk, and implies a rather minor involvement from $\mathrm{C}_{4} \mathrm{H}$ in the dissolution process.

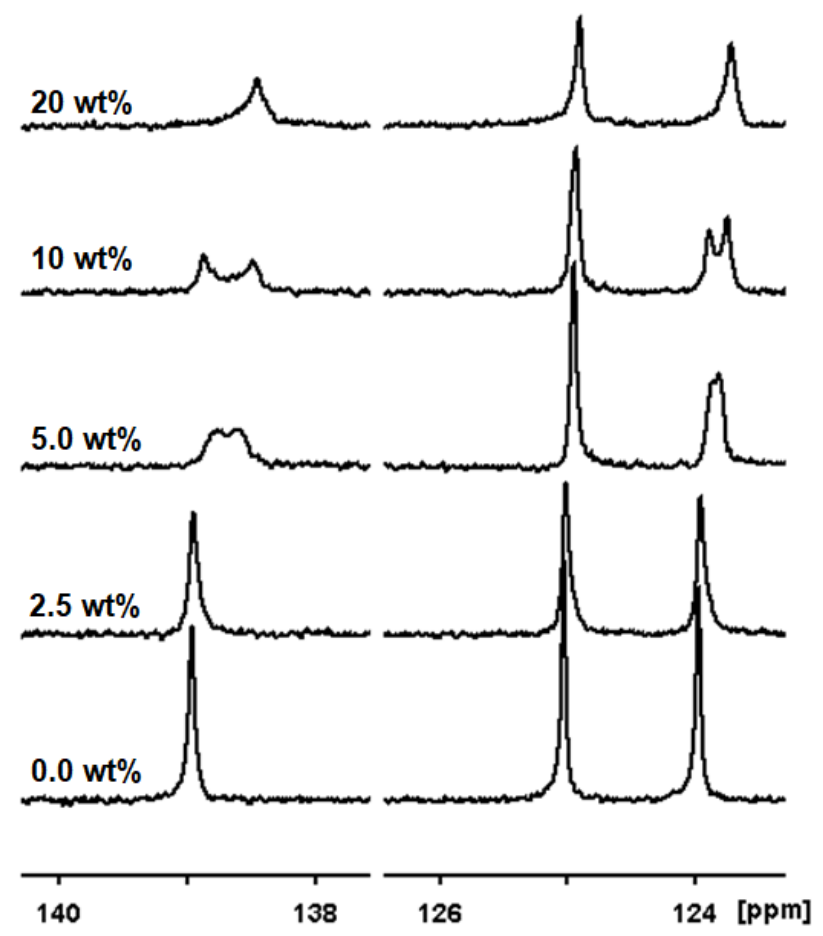

Figure 5: NMR spectra of [C $8 \mathrm{MIm}][\mathrm{Cl}]$ with increasing PMIA concentration.

The spectra also gave possible information about the constitution of the solvation shell. At $20 \mathrm{wt} \%$ the downfield peaks are gone and only the upfield peaks remain. This indicates that virtually all ionic liquid molecules are being used for the dissolution of the polymer. The amide-to-ionic liquid molar ratio at this concentration is 2:5. Furthermore, the PMIA concentration in $\left[\mathrm{C}_{8} \mathrm{MIm}\right][\mathrm{Cl}]$ can be increased to $25 \mathrm{wt} \%$, approaching a 1:2 amide-to-ionic 
liquid ratio. It is therefore plausible that the solvation shell around the polymer contains 2 $\left[\mathrm{C}_{8} \mathrm{MIm}\right][\mathrm{Cl}]$ molecules for every amide bond in the polymer.

More information on hydrogen bonding behavior can be obtained via FTIR spectroscopy, by looking at the shifts of the vibrational bands of the relevant chemical bonds. For dialkylimidazolium chlorides there are three important vibrations which are sensitive to changes in hydrogen bonding, namely, the symmetrical and asymmetrical $\mathrm{C}_{4,5}-\mathrm{H}$ stretching vibrations, and the $\mathrm{C}_{2}-\mathrm{H}$ stretching vibrations, which can be found above $3000 \mathrm{~cm}^{-1} .{ }^{57}$ These bands are generally relatively broad as a result of a distribution of hydrogen bond strengths in solution. Again a sample was made of a $20 \mathrm{wt} \%$ PMIA solution in $\left[\mathrm{C}_{8} \mathrm{MIm}\right][\mathrm{Cl}]$, and its FTIR spectrum compared to that of neat $\left[\mathrm{C}_{8} \mathrm{MIm}\right][\mathrm{Cl}]$. Both spectra are shown in Figure 6 , with the black curve representing the pure ionic liquid, and the red curve representing the solution. For both spectra, the vibrational bands for the symmetric and asymmetric $\mathrm{C}_{4,5}-\mathrm{H}$ stretching vibrations can be clearly distinguished, and these are shifted to higher wavenumbers for the solution compared to the neat ionic liquid. The symmetric peak shows a rather negligible shift from $3137 \mathrm{~cm}^{-1}$ to $3139 \mathrm{~cm}^{-1}$ upon dissolution of $20 \mathrm{wt} \%$ PMIA. However, the asymmetric peak shifts from $3040 \mathrm{~cm}^{-1}$ to $3055 \mathrm{~cm}^{-1}$. This significant upward shift of the peak is indicative of a reduced hydrogen bond strength on the $\mathrm{C}_{4,5}$ positions, as a result of the anion coordinating more with the aramid and less with the cation. This observation confirms our ${ }^{13} \mathrm{C}$ NMR results. 


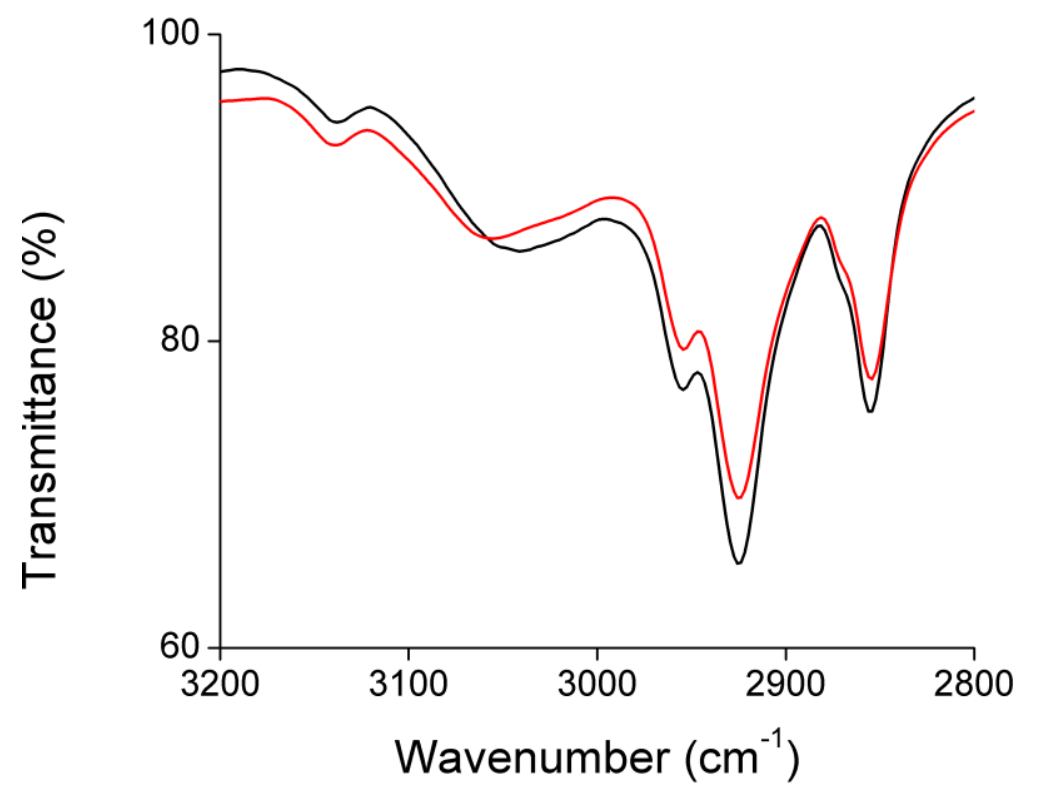

Figure 6: FTIR spectra of the C-H stretch region of neat [C $8 \mathrm{MIm}][\mathrm{Cl}]$ (black) and a solution of PMIA in [C $\mathrm{C}$ MIm][Cl] (red).

The vibrational band for the $\mathrm{C}_{2} \mathrm{H}$ stretching, which is normally found around $\sim 3020 \mathrm{~cm}^{-1}$, is obscured by other peaks in the spectrum. To counter this problem, we repeated the experiment using $\left[\mathrm{C}_{8} \mathrm{MIm}\right][\mathrm{Cl}]$ which was deuterated on the $\mathrm{C}_{2}$ position. Deuteration shifted the vibrational band to the $2000 \mathrm{~cm}^{-1}-2500 \mathrm{~cm}^{-1}$ region where it could be easily distinguished. The $\mathrm{C}_{2} \mathrm{D}$ bands for neat $\left[\mathrm{C}_{8} \mathrm{MIm}\right][\mathrm{Cl}]$, and for a $20 \mathrm{wt} \%$ PMIA solution in $\left[\mathrm{C}_{8} \mathrm{MIm}\right][\mathrm{Cl}]$ are depicted in Figure 7. The peak for pure IL at $2241 \mathrm{~cm}^{-1}$ (black curve) shifts to $2254 \mathrm{~cm}^{-1}$ upon dissolution of PMIA (red curve). This again confirms that hydrogen bonding interaction between the cation and anion is reduced as a result of dissolution of the aramid. 


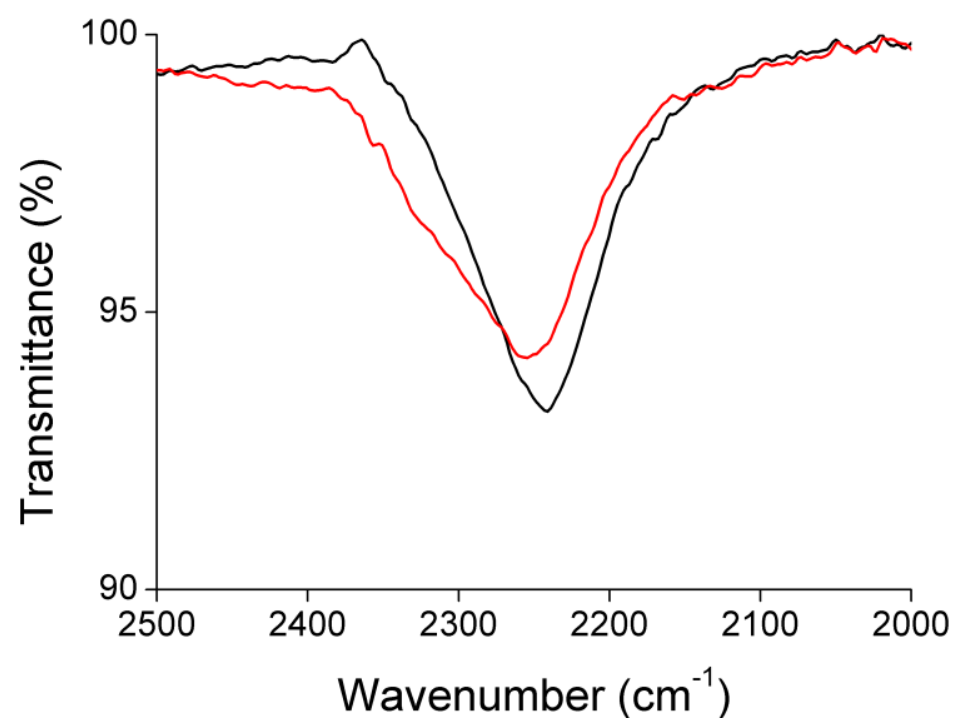

Figure 7: FTIR spectra of the deuterated $C_{2}-D$ stretching band neat [C8MIm][Cl] (black) and a solution of PMIA in $[\mathrm{C}$ MIm] [Cl] (red).

\section{Hydrogen bond interactions between the cation and the amide carbonyl}

The necessity of the presence of hydrogen bond donating sites in the cation is evident by now, but their exact role remains unclear. Upon dissolution, they experience reduced coordination but this should not be interpreted as the aromatic $\mathrm{CHs}$ being completely free. Otherwise the necessity of their presence makes no sense. As mentioned earlier, it is often suggested that hydrogen bond donors on the cation coordinate with the hydroxyl oxygen atoms of cellulose. In a similar fashion, they could interact with the amide carbonyl oxygen atoms. FTIR spectroscopy was again employed to investigate potential hydrogen bond interactions between the carbonyl group of the polymer and the cation. For these measurements we used the trimer model compounds displayed in Figure 8. The different model compounds have different degrees of steric hindrance around their carbonyl groups, which influences the strength of the hydrogen bonds. The model compound $m$-trimer O (MTO) has its carbonyl groups in close proximity to each other, leaving less space for the imidazolium cations to approach. The compounds $m$-trimer N (MTN) and $p$-trimer N (PTN), on the other hand, have more space 
available around their carbonyls, and interactions between the carbonyl groups and the imidazolium cations should proceed unhindered.<smiles>O=C(Nc1cccc(NC(=O)c2ccccc2)c1)c1ccccc1</smiles>

m-trimer N (MTN)<smiles>O=C(Nc1ccccc1)c1cccc(C(=O)Nc2ccccc2)c1</smiles><smiles></smiles>

Figure 8: Chemical structures of trimer aramid model compounds.

The asymmetrical $\mathrm{C}_{4,5}-\mathrm{H}$ stretching peak for solutions of MTO should absorb at higher wavenumbers compared to the other two model compounds, as a result of a weaker hydrogen bonding due to steric hindrance. However, from Table 5 it is clear that this was not the case. Rather, the asymmetrical $\mathrm{C}_{4,5}-\mathrm{H}$ stretching peak for solutions of MTN is found at the highest wavenumbers. This means that, in spite of the carbonyl groups being relatively accessible, the aromatic $\mathrm{CHs}$ of the imidazolium cation undergo weaker coordination. A possible explanation is that the cation does not experience any significant interaction with the carbonyl, but rather remains strongly bonded to the chloride counter anion, which on its turn is interacting with the NH hydrogen. The amide NH hydrogen atoms for MTN are the most sterically hindered, which forces the cations to remain further away from their counter anions, resulting in a weaker hydrogen bond. 
Table 5: Wavenumbers of the asymmetrical $\mathrm{C}_{4,5}-\mathrm{H}$ stretching peak of solutions of aramid trimer model compounds in different ionic liquids.

\begin{tabular}{lccc}
\hline & \multicolumn{3}{c}{ Asymmetrical $\mathrm{C}_{4,5}-\mathrm{H}$ stretching peak $\left(\mathrm{cm}^{-1}\right)$} \\
Ionic Liquid & MTN & MTO & PTN \\
\hline$\left[\mathrm{C}_{8} \mathrm{MIm}\right][\mathrm{Cl}]$ & 3055 & 3051 & 3048 \\
{$\left[\mathrm{C}_{6} \mathrm{MIm}\right][\mathrm{Cl}]$} & 3052 & 3049 & 3044 \\
{$\left[\mathrm{C}_{4} \mathrm{MIm}\right][\mathrm{Cl}]$} & 3052 & 3048 & 3047 \\
\hline
\end{tabular}

More information could be gathered by looking at the IR signal of the carbonyl group itself, namely the amide $\mathrm{I}$ band. The amide $\mathrm{I}$ band is mainly attributed to the carbonyl $\mathrm{C}=\mathrm{O}$ stretch and is therefore sensitive to changes in hydrogen bond strength. ${ }^{58}$ Figure 9 shows the 1800 $1500 \mathrm{~cm}^{-1}$ region of the FTIR spectra for PMIA (black curve) and for a solution of $20 \mathrm{wt} \%$ PMIA in $\left[\mathrm{C}_{8} \mathrm{MIm}\right][\mathrm{Cl}]$ (red curve). Upon dissolution in the ionic liquid, the amide I band shifts from $1647 \mathrm{~cm}^{-1}$ to $1664 \mathrm{~cm}^{-1}$, which indicates a weakening of the hydrogen bonds on the carbonyl. This is a result of the intermolecular hydrogen bond network breaking up due to interactions between the anion and amide $\mathrm{N}-\mathrm{H}$ hydrogen atoms. This does not necessarily negate the possibility of cation-carbonyl interactions, but they would certainly be weaker than the intermolecular hydrogen bonds.

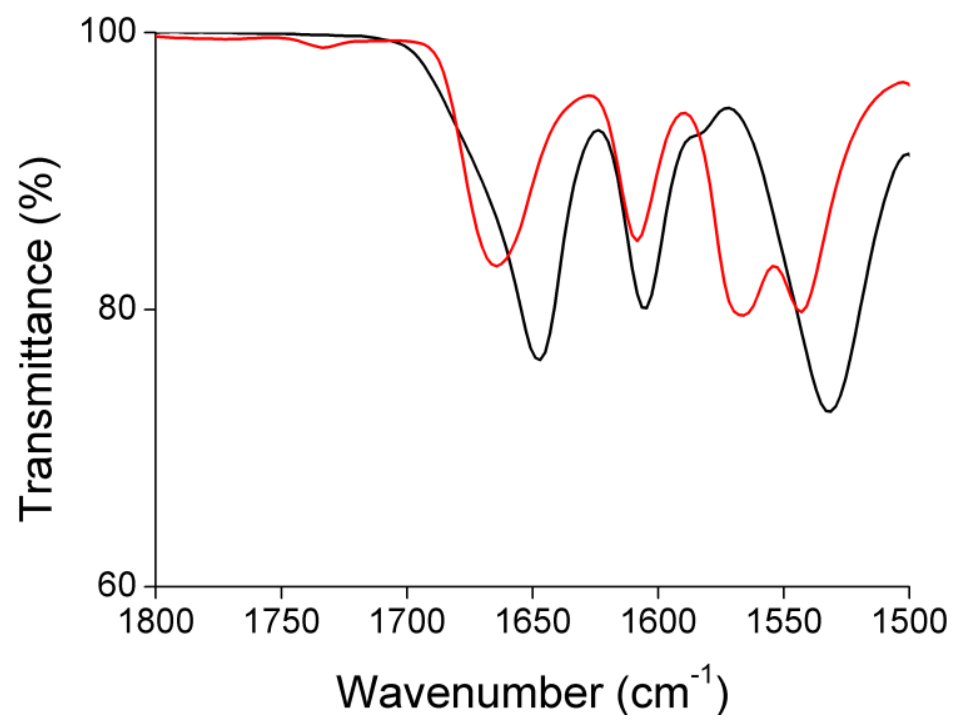

Figure 9: FTIR spectra of the Amide I bands of PMIA (black) and 20 wt\% PMIA dissolved in [C $\left.\mathrm{C}_{8} \mathrm{Im}\right][\mathrm{Cl}](\mathrm{red})$. 
Measurements were again performed using the trimer model compounds. Directly comparing the wavenumber of the amide I band for the different compounds is not possible, as it is also influenced by the relative positions of the carbonyl groups. ${ }^{59}$ However, these trimers are easily soluble in some ionic liquids that would not dissolve high molar mass PMIA. This allowed us to study differences in hydrogen bond strength on the carbonyl groups for ionic liquids with differing hydrogen bond acidities. If the cation of the ionic liquid is coordinating with the amide carbonyl, then a difference in hydrogen bond acidity should be reflected on the position of the amide I band. When looking at Table 4, however, it is clear that the type of cation had little to no influence on the position of the amide I band. Using a sterically hindered ionic liquid such as $\left[\mathrm{C}_{5} \mathrm{C}_{8} \operatorname{Im}\right][\mathrm{Cl}]$, which is a poor solvent, does not result in an upward shift of the amide I band. Nor does the use of [2-Me-C $\left.{ }_{4} \mathrm{MIm}\right][\mathrm{Cl}]$, which lacks the acidic $\mathrm{C}_{2} \mathrm{H}$ required to form hydrogen bonds. Also using the bulky quaternary ammonium and phosphonium cations, which completely lack hydrogen bond donating sites, does not have any effect on the position of the band. It is thus very likely that the interaction between the cation and the carbonyl is insignificant, and that it is not a crucial factor determining the solubility. 
Table 4: Wavenumbers of the amide I band of PMIA and aramid trimer model compounds in a range of ionic liquids. The concentration of PMIA and the aramid model compounds was $20 \mathrm{wt} \%$ or less if the maximum solubility was below 20 wt\%

\begin{tabular}{lcccc}
\hline & \multicolumn{4}{c}{ Amide I wavenumber $\left(\mathrm{cm}^{-1}\right)$} \\
Ionic Liquid & PMIA & MTN & MTO & PTN \\
\hline$\left[\mathrm{C}_{8} \mathrm{MIm}\right][\mathrm{Cl}]$ & 1664 & 1661 & 1665 & 1656 \\
{$\left[\mathrm{C}_{6} \mathrm{MIm}\right][\mathrm{Cl}]$} & 1664 & 1661 & 1665 & 1657 \\
{$\left[\mathrm{C}_{4} \mathrm{MIm}\right][\mathrm{Cl}]$} & 1665 & 1660 & 1665 & 1657 \\
{$\left[\mathrm{C}_{8} \mathrm{C}_{5} \mathrm{Im}\right][\mathrm{Cl}]$} & 1666 & 1660 & 1666 & 1656 \\
{$\left[\mathrm{C}_{2} \mathrm{MIm}\right][\mathrm{OAc}]$} & 1661 & 1659 & 1661 & 1655 \\
{$\left[\mathrm{C}_{4} \mathrm{MIm}\right][\mathrm{OAc}]$} & 1662 & 1659 & 1662 & 1655 \\
{$\left[\mathrm{C}_{2} \mathrm{MIm}\right]\left[\mathrm{PO} \mathrm{Et}_{2}\right]$} & 1665 & 1661 & 1665 & 1657 \\
{$\left[\mathrm{P}_{4442}\right]\left[\mathrm{PO} \mathrm{Et}_{2}\right]$} & $\backslash$ & 1660 & 1664 & 1654 \\
{$\left[\mathrm{P}_{14666}\right][\mathrm{Cl}]$} & $\backslash$ & 1658 & 1666 & 1655 \\
{$\left[\mathrm{P}_{4444}\right][\mathrm{Cl}]$} & $\backslash$ & 1659 & 1666 & 1655 \\
{$\left[\mathrm{~N}_{8881}\right][\mathrm{Cl}]$} & $\backslash$ & 1659 & 1666 & 1659 \\
{$\left[2-\mathrm{Me}-\mathrm{C}_{4} \mathrm{MIm}\right][\mathrm{Cl}]$} & $\backslash$ & 1658 & 1665 & 1655 \\
\hline
\end{tabular}

\section{Solvation structure}

So far, we discovered that the hydrogen bond donating $\mathrm{CHs}$ of imidazolium cations play a key role in the dissolution of PMIA. However, we found no evidence indicating that these CHs are coordinating with the carbonyl of the polymer. It is well known that in neat imidazoliumbased halide ionic liquids, all three aromatic CHs serve as hydrogen bond donors, while the halide anions can be coordinated to multiple cations. As a result, 3D networks of hydrogen bonded cations and anions are formed. ${ }^{60} \mathrm{We}$ assume that this ability to form hydrogen bond networks is required to dissolve aramids. Brooks et al. have a similar view on the solubility of cellulose in ionic liquids. ${ }^{35}$ Their idea is that the solvation shell around cellulose is a patchwork of alternating coordinated cations and anions. From this patchwork the anions interact electrostatically with the cellulose hydroxyl groups, while the imidazolium cations interact with the polymer mainly through weak dispersion interactions. We propose a similar solvation structure for PMIA in ionic liquids, as displayed in Figure 10. 

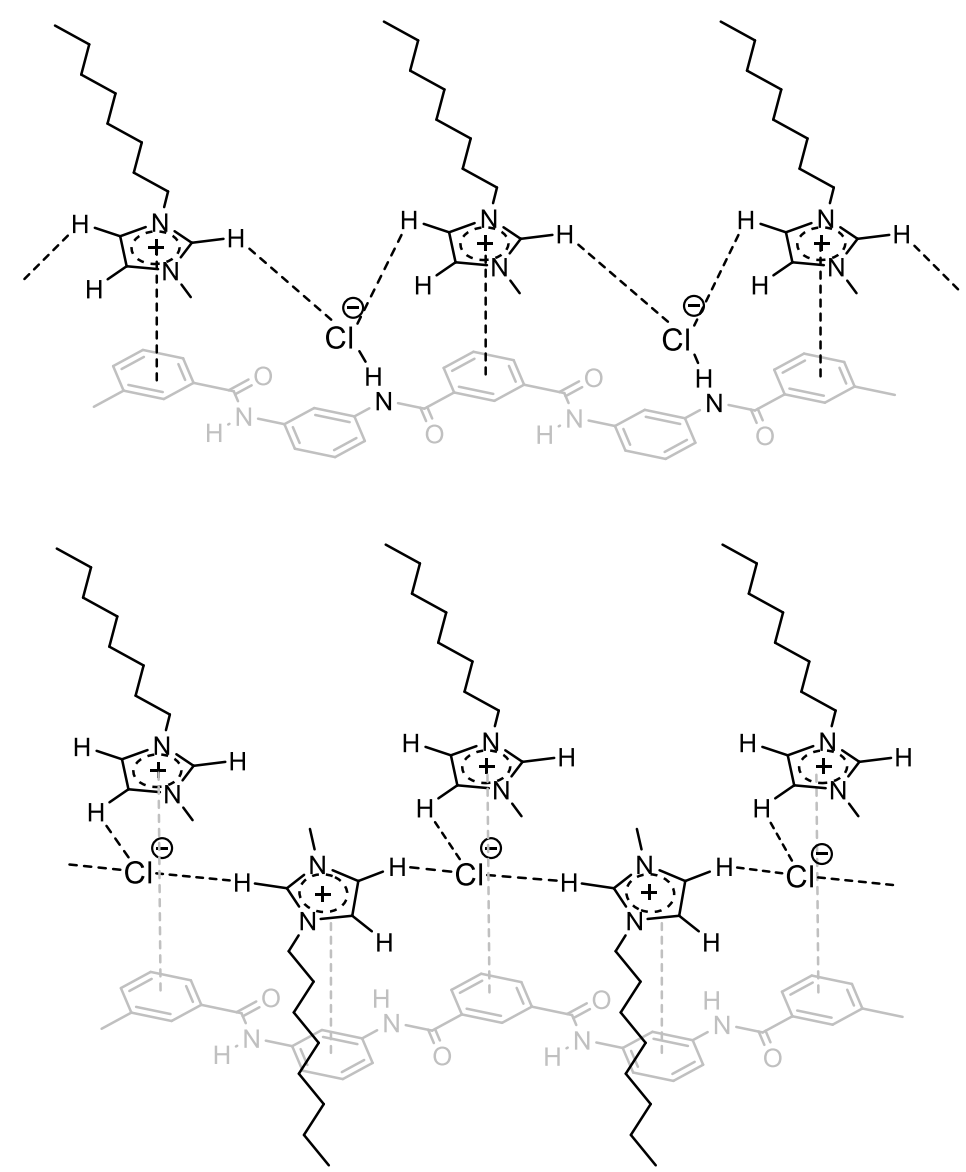

Figure 10: Simplified model of the solvation structure of PMIA in [C $8 \mathrm{MIm}][\mathrm{Cl}]$. Top: The $\mathrm{C}_{2} \mathrm{H}_{\text {'s }}$ and $\mathrm{C}_{5} \mathrm{H}_{\text {'s }}$ of [C $\left.\mathrm{C}_{8} \mathrm{MIm}\right][\mathrm{Cl}]$ are hydrogen-bonded with chloride anions that interact with the amide NH's. Bottom: The $\mathrm{C}_{4} H$ 's are coordinated with chloride anions that interact with other $\left[\mathrm{C}_{8} \mathrm{MIm}\right][\mathrm{Cl}]$ molecules, filling the gaps in the solvation shell.

Chloride (or acetate or dialkylphosphate) anions coordinate to the amide NH's, breaking up the intermolecular hydrogen bond network. The anion remains coordinated to the $\mathrm{C}_{2} \mathrm{H}$ and $\mathrm{C}_{5} \mathrm{H}$ of the cation, albeit slightly less strongly. These cation-anion interactions bring the cations in close proximity to the polymer chain, allowing weak dispersion forces with the less polar domains of the polymer (top of Figure 10). The $\mathrm{C}_{4} \mathrm{H}$ 's are coordinated to other chloride anions that are not bonded to the amide NH's. These chloride anions are provided by the ionic liquid molecules that fill the gaps in the solvation shell (bottom of Figure 10). The end result is a patchwork of cations and anions, stabilized by intramolecular hydrogen bonds, 
completely surrounding the polymer. The long alkyl chains face outward, providing steric shielding for the solvation shell.

This model is in agreement with our observations in the ${ }^{13} \mathrm{C}$ experiments. $\mathrm{C}_{2} \mathrm{H}$ and $\mathrm{C}_{5} \mathrm{H}$ experience weaker hydrogen bonding because their counter anion is shared with the polymer. On the other hand, $\mathrm{C}_{4} \mathrm{H}$ does not compete with the polymer for interaction with the anion with the polymer, and its chemical environment is not much different from in the bulk. This can explain why the $\mathrm{C}_{4}$ peak had a lower chemical shift deviation, and why no peak splitting occurred. Finally, the model is also consistent with the expected 1:2 amide-to-ionic liquid ratio in the solvation shell.

\section{Conclusions}

In this work, we have shown that some ionic liquids are strong solvents for PMIA, and could potentially serve as greener alternatives to the currently used hazardous solvents. These ionic liquids have an unsubstituted dialkylimidazolium cation and a strongly coordinating anion. The anion forms hydrogen bonds with the amide $\mathrm{NH}$ that are stronger than the intermolecular hydrogen bonds, as was shown by FTIR spectroscopy. This coordination is the main solutesolvent interaction, and serves the secondary purpose of attracting the cations towards the polymer. Dissolution tests, as well as FTIR and ${ }^{13} \mathrm{C}$ NMR measurements, indicated the importance of the presence of hydrogen-bond-donating hydrogen atoms on the imidazolium cation. No experimental evidence of any coordination between these hydrogen-bond donors and the amide carbonyl oxygen atoms was found. Rather it was suggested that their role is to stabilize the solvation shell around the polymer by coordinating strongly to the anions, creating network of hydrogen bonded anions and cations. The length of the alkyl chain on the imidazolium cations also influences the solubility of PMIA. Longer alkyl chains in the 1position of the imidazolium cation create a bulkier solvation shell, resulting in a higher solubility, up until a maximum is reached for $\left[\mathrm{C}_{8} \mathrm{MIm}\right][\mathrm{Cl}]$. Furthermore, an odd-even effect 
occurred when increasing the alkyl chain length, with even numbered chains resulting in higher solubilities. This research gives more insight in the solvent potential of ionic liquids, and furthermore widens the scope of polymer processing in ionic liquids beyond the processing of cellulose and other biopolymers.

\section{Conflict of interest}

There are no conflicts to declare.

\section{Acknowledgements}

This research was funded by a doctoral $(\mathrm{PhD})$ strategic basic research grant of the Research Foundation Flanders (FWO) to Jonas Winters (1S12717N). Teijin Aramid (Arnhem, The Netherlands) is thanked for the fruitful discussions. Assistance from Karel Duerinckx regarding the NMR measurements is greatly acknowledged. 


\section{Notes and References}

1. García, J. M.; García, F. C.; Serna, F.; de la Peña, J. L. Prog. Polym. Sci. 2010, 35 (5), 623-686.

2. $\quad$ Rao, Y.; Waddon, A. J.; Farris, R. J. Polymer 2001, 42 (13), 5937-5946.

3. Crist, B. Annu. Rev. Mater. Sci. 1995, 25 (1), 295-323.

4. $\quad$ Arpin, M.; Strazielle, C. Polymer 1977, 18 (6), 591-598.

5. Hearle, J W S. In High-Performance Fibres; Woodhead Publishing: Manchester, England, 2001.

6. Dobb, M. G.; Johnson, D. J.; Saville, B. P. J. Polym. Sci., Part B: Polym. Phys. 1977, 15 (12), 2201-2211.

7. Li, X. G.; Huang, M. R. J. Appl. Polym. Sci. 1999, 71 (4), 565-571.

8. $\quad$ Brown, J. R.; Ennis, B. C. Text. Res. J. 1977, 47 (1), 62-66.

9. Vollbracht, L.; Veerman, T. J. Process for the preparation of poly-pphenyleneterephthalamide; US Patent 4,308,374 1981.

10. Kwolek, L. S.; Winthrop, M. P.; Richard, S. W. Process of making wholly aromatic polyamides; US Patent 3,063,966 1962.

11. Scientific Committee on Consumer Safety (SCCS), "Opinion on N-Methyl-2pyrrolidone (NMP)", European Union, 2011.

12. Seddon, K. R. Ionic Liquids: "Designer" Solvents for Green Chemistry. In Methods and Reagents for Green Chemistry; Wiley: Hoboken, NJ, 2007; pp 103-130.

13. Welton, T. Chem. Rev. 1999, 99 (8), 2071-2084.

14. Wu, B.; Liu, W.; Zhang, Y.; Wang, H. Chem. - Eur. J. 2009, 15 (8), 1804-1810.

15. Mallakpour, S.; Dinari, M. Green Solvents II: Properties and Applications of Ionic Liquids; Springer Netherlands: Dordrecht, 2012; pp 1-32.

16. Swatloski, R. P.; Spear, S. K.; Holbrey, J. D.; Rogers, R. D. J. Am. Chem. Soc. 2002, 124 (18), 4974-4975.

17. Zhang, H.; Wu, J.; Zhang, J.; He, J. Macromolecules 2005, 38 (20), 8272-8277.

18. Bochek, A. M. Russ. J. Appl. Chem. 2003, 76 (11), 1711-1719.

19. Erdmenger, T.; Haensch, C.; Hoogenboom, R.; Schubert, U. S. Macromol Biosci 2007, 7 (4), 440-5.

20. Ingildeev, D.; Effenberger, F.; Bredereck, K.; Hermanutz, F. J. Appl. Polym. Sci. 2013, 128 (6), 4141-4150.

21. Cao, Y.; Li, H.; Zhang, Y.; Zhang, J.; He, J. J. Appl. Polym. Sci. 2010, 116 (1), $547-$ 554.

22. Zhang, J.; Wu, J.; Yu, J.; Zhang, X.; He, J.; Zhang, J. Mater. Chem. Front. 2017, 1 (7), 1273-1290.

23. Kuroda, K.; Miyamura, K.; Satria, H.; Takada, K.; Ninomiya, K.; Takahashi, K. ACS Sustainable Chem. Eng. 2016, 4 (6), 3352-3356.

24. Andanson, J.-M.; Bordes, E.; Devémy, J.; Leroux, F.; Pádua, A. A. H.; Gomes, M. F. C. Green Chem. 2014, 16 (5), 2528-2538.

25. Clough, M. T. Green Chem. 2017, 19 (20), 4754-4768.

26. Wang, S.; Zhao, W.; Lee, T. S.; Singer, S. W.; Simmons, B. A.; Singh, S.; Yuan, Q.; Cheng, G. ACS Sustainable Chem. Eng. 2018, 6 (3), 4354-4361.

27. Xu, A.; Wang, J.; Wang, H. Green Chem. 2010, 12 (2), 268-275.

28. Pinkert, A.; Marsh, K. N.; Pang, S. Ind. Eng. Chem. Res. 2010, 49 (22), 11121-11130.

29. Li, Y.; Liu, X.; Zhang, Y.; Jiang, K.; Wang, J.; Zhang, S. ACS Sustainable Chem. Eng. 2017, 5 (4), 3417-3428.

30. Youngs, T. G. A.; Hardacre, C.; Holbrey, J. D. J. Phys. Chem. B 2007, 111 (49), 13765-13774. 
31. Feng, L.; Chen, Z.-1. J. Mol. Liq. 2008, 142 (1), 1-5.

32. Zhang, J.; Zhang, H.; Wu, J.; Zhang, J.; He, J.; Xiang, J. Phys. Chem. Chem. Phys. 2010, 12 (8), 1941-1947.

33. Lu, B.; Xu, A.; Wang, J. Green Chem. 2014, 16 (3), 1326-1335.

34. Zhang, J.; Xu, L.; Yu, J.; Wu, J.; Zhang, X.; He, J.; Zhang, J. Sci. China: Chem. 2016, 59 (11), 1421-1429.

35. Brooks, R. D.; Agarwal, A.; Ismail, A. E. J. Phys. Chem. B 2014, 118 (6), 1621-1629.

36. Youngs, T. G. A.; Holbrey, J. D.; Mullan, C. L.; Norman, S. E.; Lagunas, M. C.;

D'Agostino, C.; Mantle, M. D.; Gladden, L. F.; Bowron, D. T.; Hardacre, C. Chem. Sci. 2011, 2 (8), 1594-1605.

37. Yuan, X.; Cheng, G. Phys. Chem. Chem. Phys. 2015, 17 (47), 31592-31607.

38. Meng, Z.; Zheng, X.; Tang, K.; Liu, J.; Ma, Z.; Zhao, Q. Int. J. Biol. Macromol. 2012, 51 (4), 440-448.

39. Xie, H.; Li, S.; Zhang, S. Green Chem. 2005, 7 (8), 606-608.

40. Phillips, D. M.; Drummy, L. F.; Conrady, D. G.; Fox, D. M.; Naik, R. R.; Stone, M.

O.; Trulove, P. C.; De Long, H. C.; Mantz, R. A. J. Am. Chem. Soc. 2004, 126 (44), 1435014351.

41. Wang, W.-T.; Zhu, J.; Wang, X.-L.; Huang, Y.; Wang, Y.-Z. J. Macromol. Sci. B 2010, 49 (3), 528-541.

42. Seitkalieva, M. M.; Grachev, A. A.; Egorova, K. S.; Ananikov, V. P. Tetrahedron 2014, 70 (36), 6075-6081.

43. $\quad$ Lozinskaya, E. I.; Shaplov, A. S.; Vygodskii, Y. S. Eur. Polym. J. 2004, 40 (9), 20652075.

44. Kamimura, A.; Yamamoto, S. Org. Lett. 2007, 9 (13), 2533-2535.

45. Vygodskii, Y. S.; Lozinskaya, E. I.; Shaplov, A. S. Macromol. Rapid Commun. 2002, 23 (12), 676-680.

46. Yavari, I.; Yavari, P.; Kowsari, E. Synth. Commun. 2009, 39 (14), 2540-2548.

47. Taghavi, M.; Alizadeh, R.; Ghaemy, M. RSC Advances 2015, 5 (13), 9581-9590.

48. Zhao, T.; Wang, H.; Zhang, Y.; Wang, B.; Jiang, J. Int. J. Mol. Sci. 2007, 8 (7), 680-

685.

49. Dewilde, S.; Dehaen, W.; Binnemans, K. Green Chem. 2016, 18 (6), 1639-1652.

50. Dewilde, S.; Vander Hoogerstraete, T.; Dehaen, W.; Binnemans, K. ACS Sustainable Chem. Eng. 2018, 6 (1), 1362-1369.

51. Dewilde, S.; Winters, J.; Dehaen, W.; Binnemans, K. Macromolecules 2017, 50 (8), 3089-3100.

52. Skrovanek, D. J.; Howe, S. E.; Painter, P. C.; Coleman, M. M. Macromolecules 1985, 18 (9), 1676-1683.

53. Ab Rani, M. A.; Brant, A.; Crowhurst, L.; Dolan, A.; Lui, M.; Hassan, N. H.; Hallett, J. P.; Hunt, P. A.; Niedermeyer, H.; Perez-Arlandis, J. M.; Schrems, M.; Welton, T.; Wilding, R. Phys. Chem. Chem. Phys. 2011, 13 (37), 16831-16840.

54. Avent, A. G.; Chaloner, P. A.; Day, M. P.; Seddon, K. R.; Welton, T. J. Chem. Soc., Dalton Trans. 1994, (23), 3405-3413.

55. Vitz, J.; Erdmenger, T.; Haensch, C.; Schubert, U. S. Green Chem. 2009, 11 (3), 417424.

56. Kurnia, K. A.; Lima, F.; Claudio, A. F. M.; Coutinho, J. A. P.; Freire, M. G. Phys. Chem. Chem. Phys. 2015, 17 (29), 18980-18990.

57. Cha, S.; Ao, M.; Sung, W.; Moon, B.; Ahlstrom, B.; Johansson, P.; Ouchi, Y.; Kim, D. Phys. Chem. Chem. Phys. 2014, 16 (20), 9591-9601.

58. H., M. W.; S., K. Biopolymers 1976, 15 (12), 2439-2464. 
59. Skrovanek, D. J.; Painter, P. C.; Coleman, M. M. Macromolecules 1986, 19 (3), 699705.

60. Dong, K.; Zhang, S.; Wang, D.; Yao, X. J. Phys. Chem. A 2006, 110 (31), 9775-9782. 